\title{
Thermal Decomposition Behavior of Melaminium Benzoate Dihydrate
}

\author{
N. Kanagathara, ${ }^{1}$ M. K. Marchewka, ${ }^{2}$ K. Pawlus, ${ }^{2}$ S. Gunasekaran, ${ }^{3}$ and G. Anbalagan ${ }^{4}$ \\ ${ }^{1}$ Department of Physics, Vel Tech Multi Tech Dr. Rangarajan Dr. Sakunthala Engineering College, Avadi, Chennai 62, India \\ ${ }^{2}$ Institute of Low Temperature and Structure Research, Polish Academy of Sciences, 2, P.O. Box 937, 50-950 Wrockaw, Poland \\ ${ }^{3} P G$ \& Research Department of Physics, Pachaiyappa's College, Chennai 30, India \\ ${ }^{4}$ Department of Physics, Presidency College, Chennai 5, India
}

Correspondence should be addressed to G. Anbalagan; anbu24663@yahoo.co.in

Received 5 April 2013; Accepted 5 June 2013

Academic Editor: Guennadi E. Zaikov

Copyright (c) 2013 N. Kanagathara et al. This is an open access article distributed under the Creative Commons Attribution License, which permits unrestricted use, distribution, and reproduction in any medium, provided the original work is properly cited.

Crystals of melaminium benzoate dihydrate (MBDH) have been grown from aqueous solution by slow solvent evaporation method at room temperature. Powder X-ray diffraction analysis confirms that MBDH crystallizes in the monoclinic system $(C 2 / c)$. Thermal decomposition behavior of $\mathrm{MBDH}$ has been studied by thermogravimetric analysis at three different heating rates: 10,15 , and $20^{\circ} \mathrm{C} / \mathrm{min}$. Nonisothermal studies of $\mathrm{MBDH}$ revealed that the decomposition occurs in three stages. The values of effective activation energy $\left(E_{a}\right)$ and preexponential factor $(\ln A)$ of each stage of thermal decomposition for all heating rates were calculated by model free methods: Arrhenius, Flynn-Wall, Friedman, Kissinger, and Kim-Park methods. A significant variation of effective activation energy $\left(E_{a}\right)$ with conversion $(\alpha)$ indicates that the process is kinetically complex. The linear relationship between the $A$ and $E_{a}$ values was established (compensation effect). Avrami-Erofeev model (A3), contracting cylinder (R2), and Avrami-Erofeev model (A4) were accepted by stages I, II, and III, respectively. DSC has also been performed.

\section{Introduction}

Supramolecular chemistry is the chemistry of molecular aggregates assembled via noncovalent interactions [1]. The design and synthesis of supramolecular polymeric networks, especially those constructed by hydrogen bonding and intermolecular weak interactions have attracted by many researchers due to their physical properties and potential applications in functional materials. Melamine and its organic and inorganic complexes or salts can develop supramolecular structures via multiple hydrogen bonds containing components that contain complementary arrays of hydrogen bonding sites [2-5]. The crystal structure of melaminium benzoate dihydrate was already reported [6]. The asymmetric unit of melaminium benzoate dihydrate $\left(\mathrm{C}_{3} \mathrm{H}_{7} \mathrm{~N}_{6}{ }^{+} \cdot \mathrm{C}_{6} \mathrm{H}_{5} \mathrm{COO}^{-} \cdot 2 \mathrm{H}_{2} \mathrm{O}\right)$ consists of singly protonated melaminium cations, benzoate anions, and water molecules. The components are linked by hydrogen bonds into a three dimensional framework structure. Several researchers have already studied the thermal behavior of melamine and its salts [7-12]. The presence of triazine ring in the melamine structure gives improved hydrolytic and thermal stability [13]. TGA is a commonly used technique to determine characteristics of thermal decomposition kinetics and thermal stability of polymers and its composites. This can be done by either single heating rate program like Coats-Redfern, FreemanCarroll, and Chang or multiple heating rate programs like Flynn-Wall, Friedman, Kissinger, and Kim-Park [14-17]. To estimate kinetic parameters for the thermal decomposition of polymer composites, multiple heating rate method is recommended by the ICTAC committee [18].

\section{Experimental Procedure}

2.1. Preparation of $M B D H$. MBDH crystal was synthesized from melamine and benzoic acid in the stoichiometric ratio 


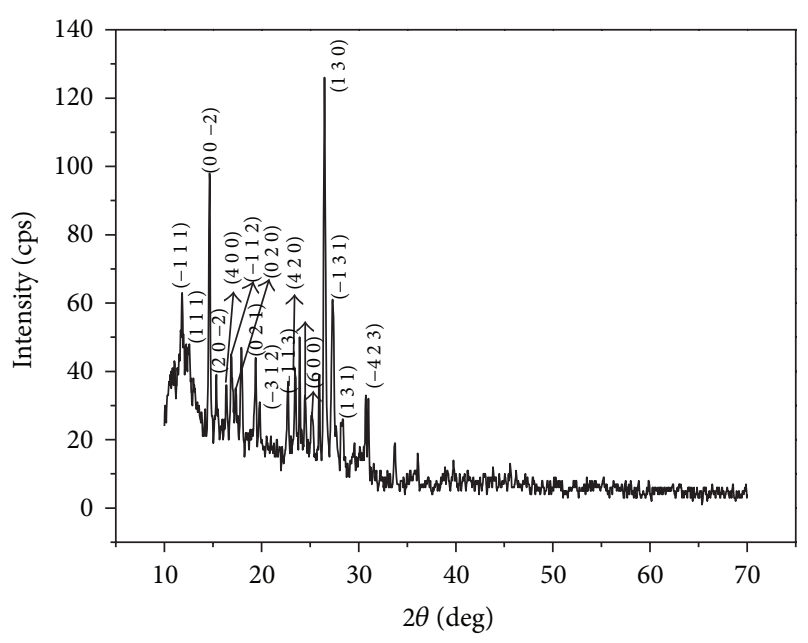

FIgURE 1: Powder X-ray diffraction pattern of $\mathrm{MBDH}$.

$1: 1$. To the hot solution of melamine, benzoic acid solution was added gently and stirred continuously well for 5 hours to get the homogenous solution. Then the solution was allowed to evaporate at room temperature, which yielded needle shaped crystals within a period of 20-25 days.

2.2. Characterization. The grown crystals of $\mathrm{MBDH}$ have been characterized by X-ray powder diffraction technique using Rich Seifert X-ray powder diffractometer with $\mathrm{CuK}_{\alpha}$ radiation of $\lambda=1.5406 \AA$. The $2 \theta$ range was analyzed from $10^{\circ}$ to $70^{\circ}$ by employing the reflection mode for scanning. The detector used was a scintillation counter. The thermal behavior of the crystal was determined by thermogravimetric analysis and differential thermal analysis using an SDT Q $6000 \mathrm{~V} 8.2$ Built 100 thermal analyzer at a heating rate of 10,15 and $20^{\circ} \mathrm{C} / \mathrm{min}$ under nitrogen atmosphere in the temperature range of $30-1000^{\circ} \mathrm{C}$. DSC was carried out on NETZSCH DSC 204 analyzer with an initial mass of $3.850 \mathrm{mg}$ in the temperature range $0-120^{\circ} \mathrm{C}$.

\section{Results and Discussion}

3.1. X-Ray Powder Diffraction Analysis. Figure 1 shows the indexed X-ray powder diffraction pattern for the grown $\mathrm{MBDH}$ crystal. From the study, it is confirmed that the title crystal crystallizes in monoclinic system $(\mathrm{C} 2 / \mathrm{c})$ with the lattice parameters $a=21.878 \pm 0.039 \AA, b=9.859 \pm 0.023 \AA$, $c=12.547 \pm 0.027 \AA, \alpha=90.00 \pm 0.00^{\circ}, \beta=99.02 \pm 0.24^{\circ}$, $\gamma=90.00 \pm 0.00^{\circ}$, and $V=2672.92 \AA^{3}$ and it agrees very well with the earlier literature [6]. The prominent peaks have been indexed.

3.2. Thermal Analysis. TG-DTG curves of $\mathrm{MBDH}$ at three different heating rates 10,15 , and $20^{\circ} \mathrm{C} / \mathrm{min}$ in the temperature range of $30-1000^{\circ} \mathrm{C}$ are shown in Figure 2 and it seems that TG curve exhibits mass losses in three stages involving dehydration and decomposition. For $10^{\circ} \mathrm{C} / \mathrm{min}$, the initial mass is taken as $1.3490 \mathrm{mg}$. The first stage of decomposition takes

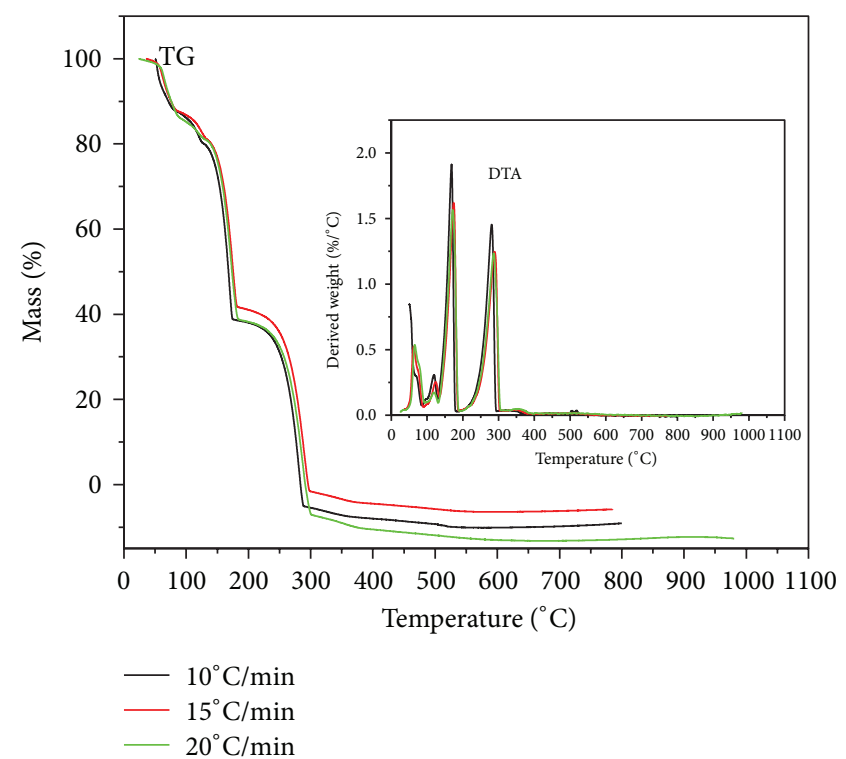

FIGURE 2: TG-DTA curves of $\mathrm{MBDH}$ in nitrogen atmosphere; heating rate of 10,15 and $20^{\circ} \mathrm{C} \mathrm{min}^{-1}$.
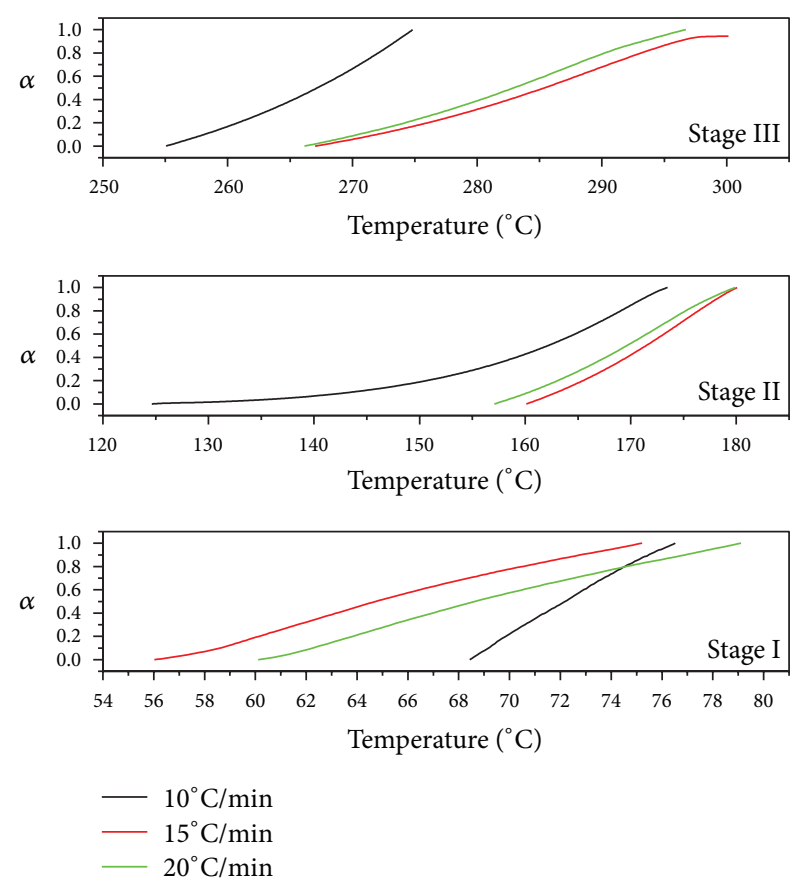

FIGURE 3: Fraction reacted, $\alpha$, versus temperature for stages I, II, and III at three different heating rates.

place in the temperature range of $68.48^{\circ} \mathrm{C}$ to $111.86^{\circ} \mathrm{C}$ with a weight loss of $4.691 \%$ and is due to the liberation of two water molecules from the structure of $\mathrm{MBDH}$. The corresponding exothermic peak is seen at $63.04^{\circ} \mathrm{C}$. A rapid weight loss starts at $124.65^{\circ} \mathrm{C}$ and continues up to $173.45^{\circ} \mathrm{C}$ with a weight loss of $41.78 \%$. This mass loss is attributed to the decomposition of benzoate anions. It exactly matches with an exothermic peak at $169.05^{\circ} \mathrm{C}$ in DTG curve. And the remaining $37.78 \%$ 
TABLE 1: Activation energies of thermal degradation of MBDH by Arrhenius, Kissinger, and Kim-Park methods.

\begin{tabular}{lcccccc}
\hline \multirow{2}{*}{ Method } & \multirow{2}{*}{${\text { Heating rate/ }{ }^{\circ} \mathrm{C} \mathrm{min}^{-1}}^{*}$} & \multicolumn{2}{c}{ Stage I } & \multicolumn{2}{c}{ Stage II } & \multicolumn{2}{c}{$\begin{array}{c}\text { Stage III } \\
\ln A / \mathrm{s}^{-1}\end{array}$} \\
\hline \multirow{3}{*}{ Arrhenius } & 10 & 41.92 & 13.60 & 89.97 & 27.52 & 115.11 \\
& 15 & 40.01 & 12.25 & 62.96 & 20.15 & 85.32 \\
Kissinger & 20 & 29.27 & 8.02 & 63.41 & 20.64 & 82.59 \\
Kim-Park & & 83.54 & 20.67 & 122.48 & 26.39 & 184.23 \\
\hline
\end{tabular}

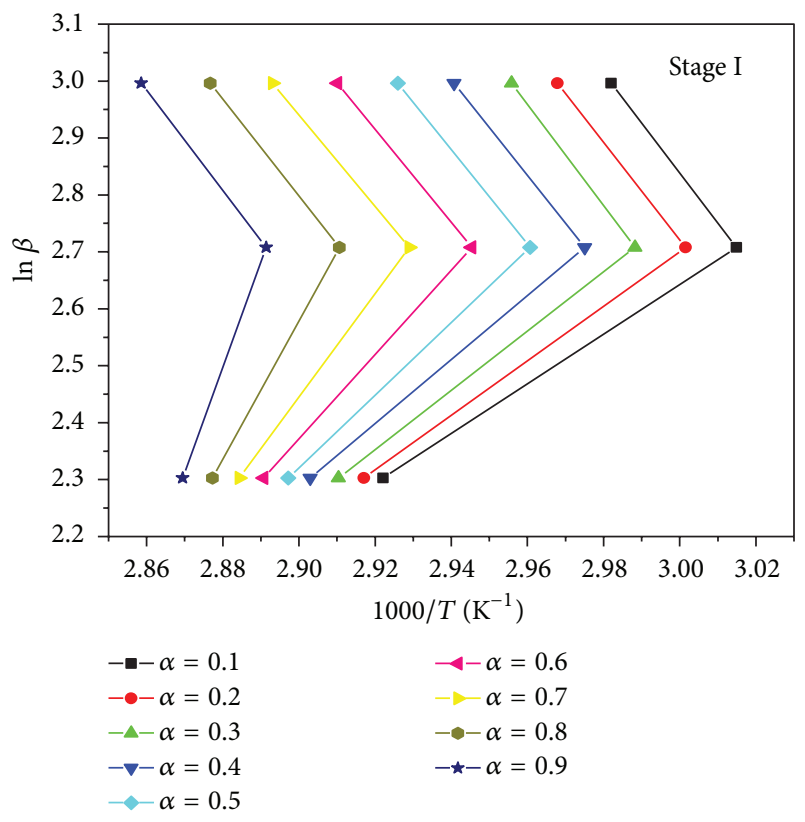

FIGURE 4: Flynn-Wall plot for stage I in nitrogen atmosphere for the nonisothermal decomposition of MBDH using TG data.

of weight loss occurs in the range $254.93^{\circ} \mathrm{C}-274.84^{\circ} \mathrm{C}$ and it is due to the decomposition of melamine with a final residue of $0.02188 \mathrm{mg}$. This is accompanied by an exothermic peak at $281.36^{\circ} \mathrm{C}$. There is a good agreement between the expected and observed mass losses for the loss of two water molecules, one melaminium cation and benzoate anions. Heating rate and atmosphere have significant influence on the thermal decomposition of a material [19]. Dehydration exothermic peak at $63.04^{\circ} \mathrm{C}$ is shifted to $63.45^{\circ} \mathrm{C}$ and $65.63^{\circ} \mathrm{C}$ for 15 and $20^{\circ} \mathrm{C} / \mathrm{min}$, respectively. Similarly benzoate anion shows its DTG peak at $172.92^{\circ} \mathrm{C}$ and $175.46^{\circ} \mathrm{C}$ and melaminium cation decomposition shows its DTG peak at $288.63^{\circ} \mathrm{C}$ and $289.33^{\circ} \mathrm{C}$ for 15 and $20^{\circ} \mathrm{C} / \mathrm{min}$, respectively. Thus when the heating rate is increased to 15 and $20^{\circ} \mathrm{C} / \mathrm{min}$, all exothermic peaks in DTG curve are shifted to higher temperatures which is clearly seen in Figure 2.

In order to obtain the thermal kinetic parameters (activation energy $E_{a}$, preexponential factor $\ln A$ ), multiple heating rate methods, Flynn-Wall, Friedman, Kissinger, and KimPark methods, were employed [14-17]. TGA kinetics analysis is determined by measurement of fractional mass loss and

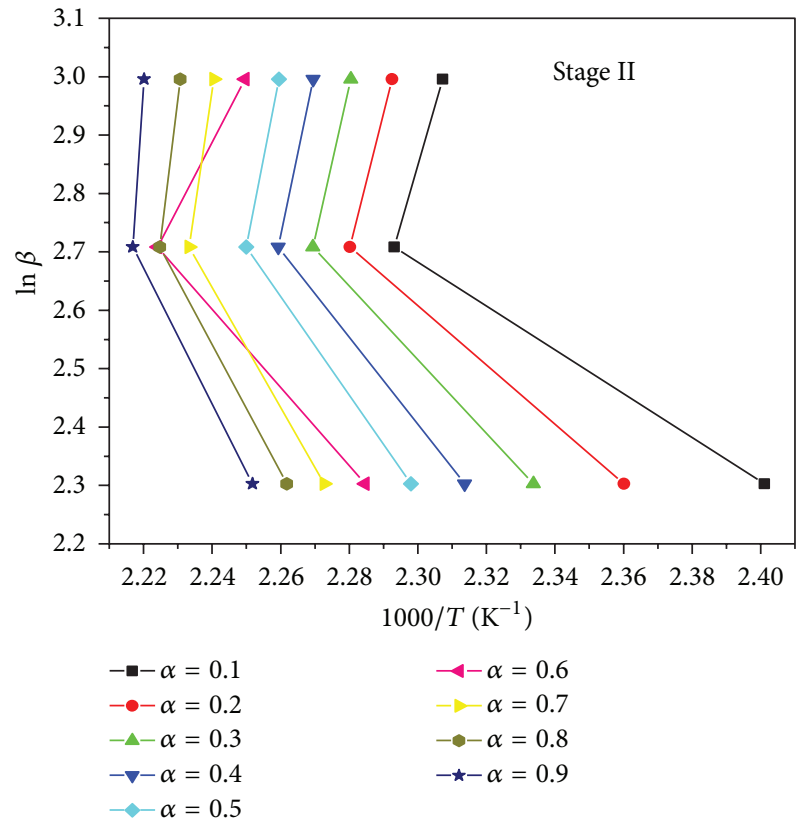

FIGURE 5: Flynn-Wall plot for stage II in nitrogen atmosphere for the nonisothermal decomposition of $\mathrm{MBDH}$ using TG data.

degradation rate according to temperature change. The fraction of conversion $(\alpha)$ is defined as

$$
\alpha=\left[\frac{W_{o}-W}{W_{o}-W_{f}}\right],
$$

where $W$ is the actual weight at any degradation time, $W_{o}$ is the initial weight, and $W_{f}$ is the final weight at the end of thermal degradation process. The rate of degradation, $d \alpha / d t$, can be expressed as the product of the function of temperature and the function of conversion:

$$
\frac{d \alpha}{d t}=\beta \frac{d \alpha}{d t}=k(T) \cdot f(\alpha),
$$

where $\beta=d T / d t$ is the heating rate.

For nonisothermal experiments, the reaction rate at all times depends on both $f(\alpha)$ and $k(T)$. Hence generally $f(\alpha)$, $k(T)$, and $\ln A$ are known as kinetic triplet.

The temperature dependent function is generally assumed to follow an Arrehenius type dependency:

$$
\ln k=\ln A-\frac{E_{a}}{R T} .
$$


TABLE 2: Kinetic parameters of non-isothermal decomposition of MBDH by Flynn-Wall and Friedman methods.

\begin{tabular}{|c|c|c|c|c|c|c|c|c|c|c|c|c|}
\hline \multirow{3}{*}{$\alpha$} & \multicolumn{6}{|c|}{ Flynn-Wall } & \multicolumn{6}{|c|}{ Friedman } \\
\hline & \multicolumn{2}{|c|}{ Stage I } & \multicolumn{2}{|c|}{ Stage II } & \multicolumn{2}{|c|}{ stage III } & \multicolumn{2}{|c|}{ Stage I } & \multicolumn{2}{|c|}{ Stage II } & \multicolumn{2}{|c|}{ Stage III } \\
\hline & $E_{a} / \mathrm{kJ} \mathrm{mol}^{-1}$ & $\ln A / \mathrm{s}^{-1}$ & $E_{a} / \mathrm{kJ} \mathrm{mol}^{-1}$ & $\ln A / \mathrm{s}^{-1}$ & $E_{a} / \mathrm{kJ} \mathrm{mol}^{-1}$ & $\ln A / s^{-1}$ & $E_{a} / \mathrm{kJ} \mathrm{mol}^{-1}$ & $\ln A / s^{-1}$ & $E_{a} / \mathrm{kJ} \mathrm{mol}^{-1}$ & $\ln A / \mathrm{s}^{-1}$ & $E_{a} / \mathrm{kJ} \mathrm{mol}^{-1}$ & $\ln A / \mathrm{s}^{-1}$ \\
\hline 0.1 & 43.59 & 11.26 & 42.13 & 12.87 & 95.37 & 21.48 & 11.65 & 3.77 & 47.79 & 14.25 & 30.83 & 7.56 \\
\hline 0.2 & 45.76 & 11.93 & 56.68 & 16.50 & 88.32 & 19.86 & 19.34 & 6.46 & 49.82 & 14.88 & 37.36 & 9.08 \\
\hline 0.3 & 48.62 & 12.82 & 70.04 & 19.87 & 82.49 & 18.54 & 25.13 & 8.47 & 43.99 & 13.35 & 40.44 & 9.81 \\
\hline 0.4 & 48.49 & 12.71 & 82.44 & 22.99 & 78.93 & 17.71 & 27.34 & 9.22 & 28.57 & 9.21 & 42.56 & 10.33 \\
\hline 0.5 & 48.86 & 12.76 & 93.02 & 25.64 & 75.54 & 16.94 & 27.22 & 9.16 & 14.43 & 3.19 & 41.78 & 10.21 \\
\hline 0.6 & 45.91 & 11.72 & 62.34 & 17.55 & 72.73 & 16.29 & 24.75 & 8.28 & 14.91 & 2.42 & 36.62 & 9.10 \\
\hline 0.7 & 34.27 & 7.88 & 113.93 & 30.86 & 69.78 & 15.64 & 19.56 & 6.46 & 61.59 & 14.98 & 23.71 & 6.29 \\
\hline 0.8 & 12.25 & 1.19 & 122.09 & 32.86 & 66.45 & 14.91 & 12.79 & 4.09 & 91.21 & 22.93 & 8.92 & 0.92 \\
\hline 0.9 & 39.89 & 14.88 & 130.86 & 35.00 & 62.41 & 14.05 & 11.02 & 1.25 & 79.69 & 19.94 & 44.27 & 8.54 \\
\hline
\end{tabular}

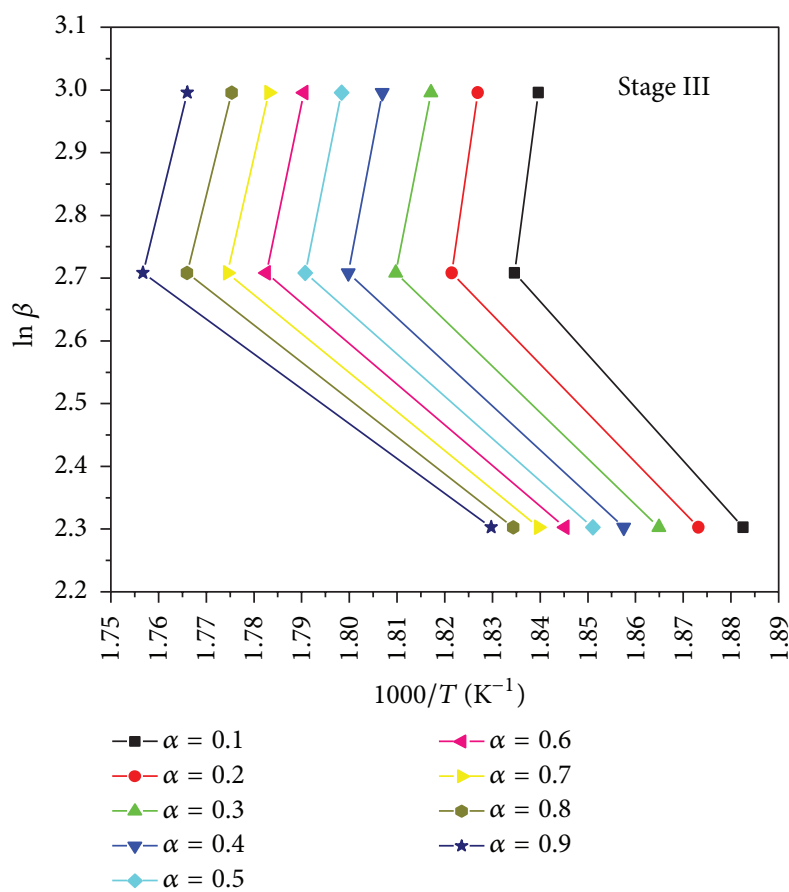

FIGURE 6: Flynn-Wall plot for stage III in nitrogen atmosphere for the nonisothermal decomposition of $\mathrm{MBDH}$ using TG data.

A typical plot of $\alpha$ versus temperature for stages I, II, and III is shown in Figure 3. It is seen that all $\alpha-T$ curves have the same shapes. From the slope of linear Arrhenius plots of $\ln k$ versus $1 / T$ for the thermal decomposition of $\mathrm{MBDH}$ at three different heating rates, the activation energies $\left(E_{a}\right)$ for all stages were calculated and listed in Table 1. Activation energies of the decomposition complex were also calculated by Kissinger and Kim-Park. Both methods yield similar calculation results, which are therefore reasonable (Table 1).

Flynn-Wall plots for three different heating rates against the temperature for the stages I, II, and III are shown in Figures 4, 5, and 6, respectively, and the straight lines obtained are nearly parallel to each other. At each heating rate, the temperatures were determined corresponding to the degree of conversion $\alpha$ within the range 0.1 to 0.9 in intervals of 0.1 . Activation energy $\left(E_{a}\right)$ is calculated from the slope of $\ln \beta$ versus $1 / T$ for a fixed mass loss and it is given in Table 2. We have also calculated the activation energies by Friedman method for all the three stages and they are given in Table 2. The calculated values of the activation energy in the Flynn-Wall method very well agree with the Friedman. If $E_{a}$ changes with $\alpha$, the process is complex and the shape of $E_{a}-\alpha$ curve may provide the information on the reaction mechanism $[20,21]$. With increasing heating rate, TG curves shifted to higher temperature which is a typical case of thermally activated heterogenous process. The mass loss depends on the heating rate. Mass loss is very small at the lowest heating rate and high at the highest heating rate.

Figure 7(a) shows the dependence of the apparent activation energy $\left(E_{a}\right)$ on the degree of conversion $(\alpha)$ obtained by Flynn-Wall method. Dependence of effective activation energy $\left(E_{a}\right)$ with extent of conversion $(\alpha)$ is used to identify its kinetic scheme; that is, these values are used for input to multistep for model fitting purposes. Kinetic compensation effect was observed in many isothermal processes. There is a linear relationship between $\ln A$ and $E_{a}$ :

$$
\ln A=a E+b
$$

where $a$ and $b$ are called compensation parameters. Figure 7(b) shows the linear relationship between $\ln A$ and $E_{a}$ and hence it is clear that compensation effect is valid for the thermal decomposition of MBDH.

Best models can be selected by introducing the various analytical forms of $g(\alpha)$ and $f(\alpha)$ functions at all heating rates $(\beta)$ which in turn depend on the value of statistical parameters $R$. A plot of $\ln g(\alpha) / T^{2}$ versus $1000 / T$ that gives straight line for all the three stages is shown in Figure 8 accompanied by a correlation value $0.9-0.99$. Dehydration was governed by Avrami-Erofeev model (A3), decomposition of benzoate anion was governed by contracting cylinder (R2) 


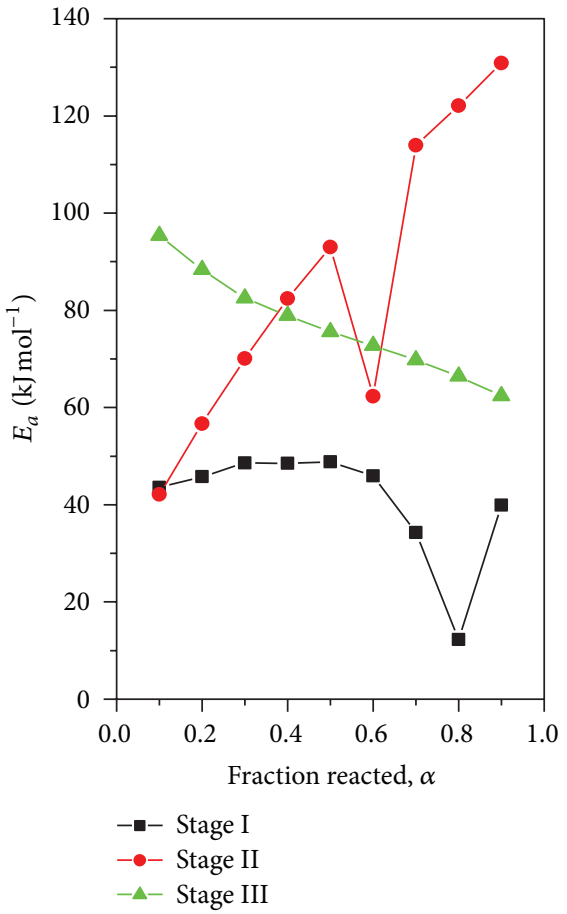

(a)

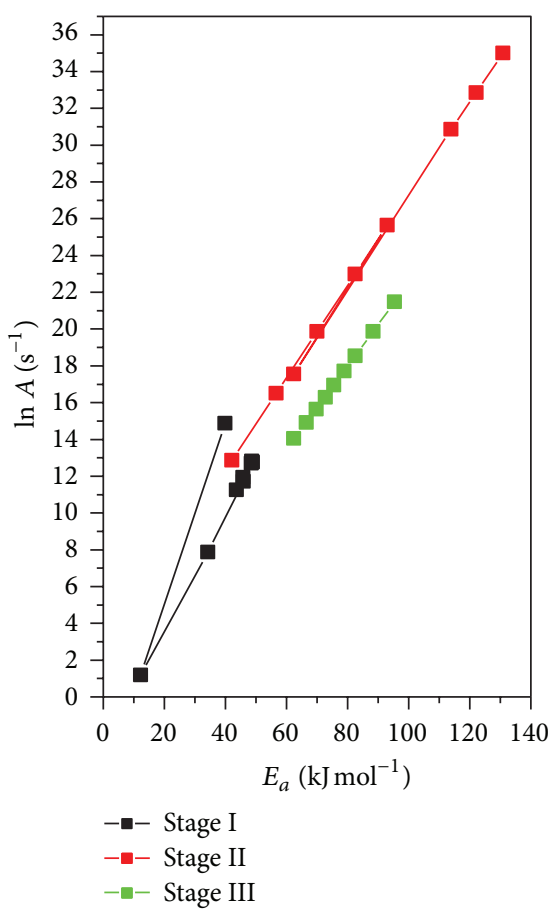

(b)

FIGURE 7: (a) Variation of effective activation energy $\left(E_{a}\right)$ versus fraction reacted $(\alpha)$ by Flynn-Wall method for the three different stages I, II, and III. (b) Compensation effect plot.

model, and melaminium cation decomposition was accepted by Avrami-Erofeev model (A4).

3.3. Phase Transition. Figure 9 shows the DSC traces of MBDH. Differential Scanning Calorimetry measurements indicate clearly the occurrence of phase transition of the first order at approximately 368 and $358 \mathrm{~K}$ for heating and cooling, respectively, which is accompanied by a big thermal effect of $385 \mathrm{~J} / \mathrm{g}$. The peak at $95^{\circ} \mathrm{C}$ is due to the water of crystallization of $\mathrm{MBDH}$. The phase transition of the benzoate anion occurs at $158.6^{\circ} \mathrm{C}$ and $167.3^{\circ} \mathrm{C}$ for heating and cooling, respectively, accompanied by a thermal effect of $17.54 \mathrm{~J} / \mathrm{g}$ and $2.049 \mathrm{~J} / \mathrm{g}$. The third stage of thermal decomposition is the elimination of melamine which is usually occurs at $\sim 500-600^{\circ} \mathrm{C}$. In the present study, it is not the objective to find out the decomposition temperature of the final compound. The thermal stability of melamine is naturally higher since it has strong intermolecular hydrogen bonding which is expected to be present in these structures because of water of crystallization.

\section{Conclusions}

Single crystals of melaminium benzoate dihydrate $(\mathrm{MBDH})$ crystallize in the monoclinic system $(C 2 / c)$. TG-DTG measurements were carried out at three different heating rates: 10,15 , and $20^{\circ} \mathrm{C} / \mathrm{min}$. Model free methods, Arrhenius,
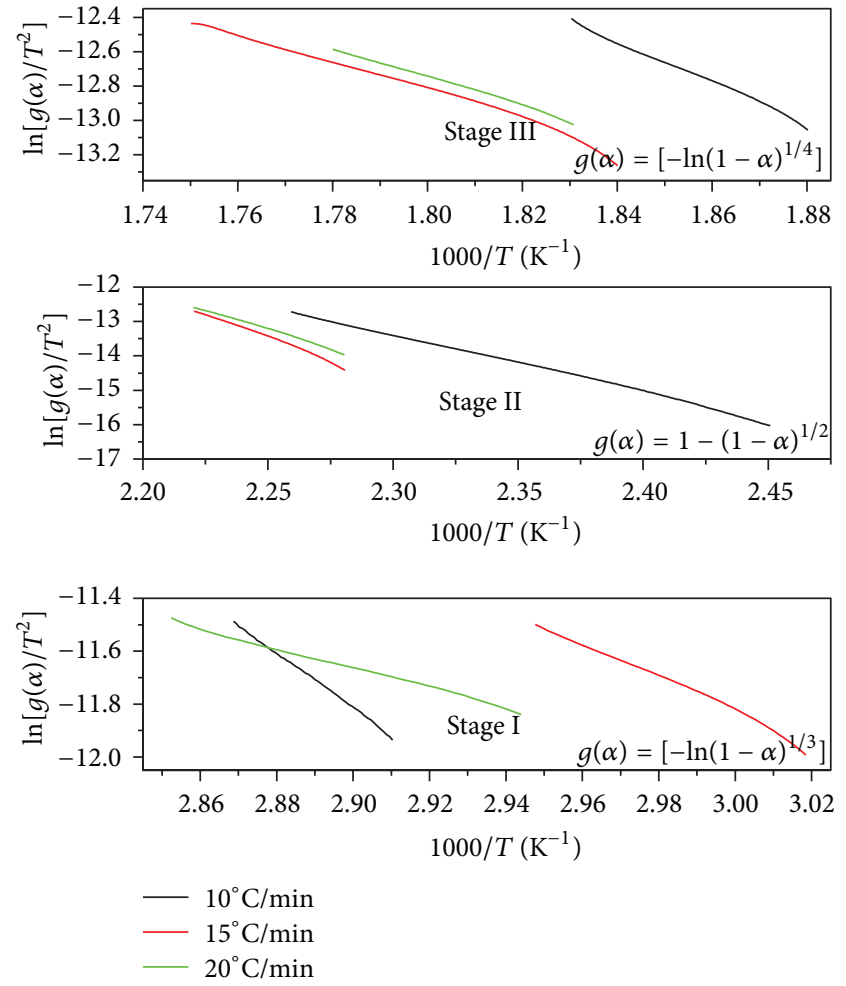

FIGURE 8: Plot of $\ln \left[g(\alpha) / T^{2}\right]$ versus $1000 / T$ for stages I, II, and III using TG data. 


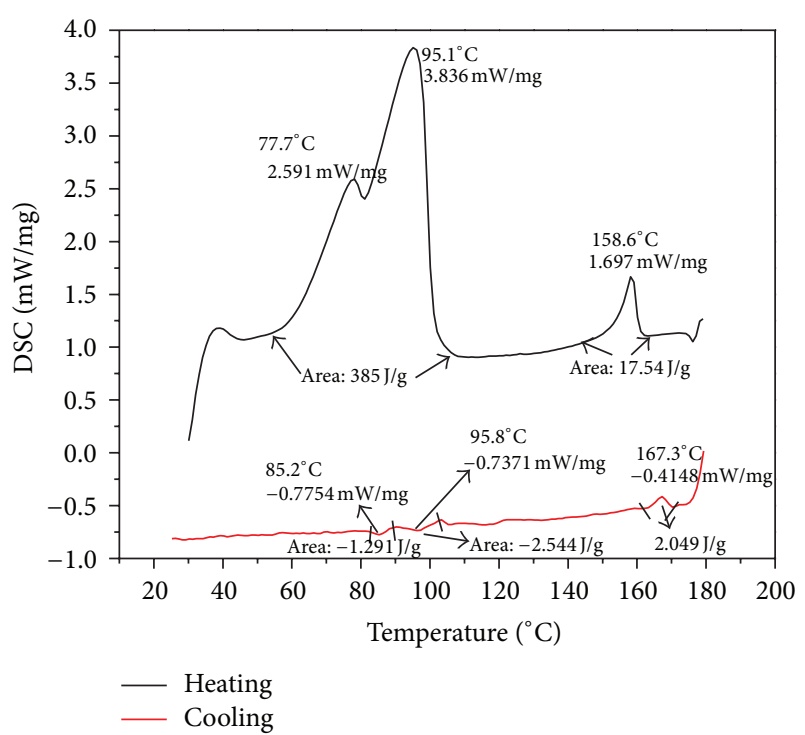

Figure 9: DSC traces of MBDH.

Flynn-Wall, Friedman, Kissinger, and Kim-Park methods, were employed. All methods yield almost similar results. It is found that Kissinger and Kim-Park are the most suitable methods to find effective activation energy. Effective activation is nearly constant for stage I whereas it varies strongly with extent of conversion for the stages II and III indicating that the process is dominated by multistep mechanism. The compensation effect is valid for the thermal decomposition of $\mathrm{MBDH}$. From the results, it is concluded that Avrami Erofeev model (A3) is the most probable kinetic model for the thermal decomposition of $\mathrm{MBDH}$ for the dehydration stage, contracting cylinder (R2) for the benzoate anion decomposition, and Avrami-Erofeev model (A4) for the decomposition of melaminium cation.

\section{References}

[1] M. J. Lehn, Supramolecular Chemistry, VCI-I, Weinheim, Germany, 1995.

[2] G. R. Desiraju, "Supramolecular synthons in crystal engineering. A new organic synthesis," Angewandte Chemie, vol. 34, p. 2311, 1995.

[3] J. C. MacDonald and G. M. Whitesides, "Solid-state structures of hydrogen-bonded tapes based on cyclic secondary diamides," Chemical Reviews, vol. 94, no. 8, pp. 2383-2420, 1994.

[4] T. N. Guru Row, "Hydrogen and fluorine in crystal engineering: systematics from crystallographic studies of hydrogen bonded tartrate-amine complexes and fluoro-substituted coumarins, styrylcoumarins and butadienes," Coordination Chemistry Reviews, vol. 183, no. 1, pp. 81-100, 1999.

[5] M. J. Krische and J. M. Lehn, "The utilization of persistent Hbonding motifs in the self-assembly of supramolecular architectures," Structure and Bonding, vol. 96, pp. 3-29, 2000.

[6] G.J. Perpetuo and J. Janczak, "Melaminium benzoate dihydrate," Acta Crystallographica, vol. E61, pp. o287-o289, 2005.

[7] L. Costa and G. Camino, "Thermal behaviour of melamine," Journal of Thermal Analysis, vol. 34, no. 2, pp. 423-429, 1988.
[8] W. Y. Chen, Y. Z. Wang, and F. C. Chang, "Flame retardation and thermal properties of melamine phosphate containing epoxy resins," Journal of Polymer Research, vol. 11, no. 5, p. 109, 2004.

[9] D. L. Yu, J. L. He, Z. Y. Liu et al., "Phase transformation of melamine at high pressure and temperature," Journal of Materials Science, vol. 43, pp. 689-695, 2008.

[10] H. May, "Pyrolysis of melamine," Journal of Applied Chemistry, vol. 9, pp. 340-344, 1959.

[11] X. G. Li, "Thermogravimetric kinetics of thermotropic copolyesters containing p-oxybenzoate unit by multiple heating-rate methods," Journal of Applied Polymer Science, vol. 74, no. 8, pp. 2016-2028, 1999.

[12] N. Kanagathara, M. K. Marchewka, N. Sivakumar et al., "A study of thermal and dielectric behavior of melaminium perchlorate monohydrate single crystals," Journal of Thermal Analysis and Calorimetry, vol. 112, pp. 1317-1323, 2013.

[13] K. Siimer, P. Cristjanson, T. Kaljuvee, T. Pekh, I. Lasn, and I. Saks, "TG-DTA study of melamine-urea-formaldehydre resins," Journal of Thermal Analysis and Calorimetry, vol. 92, pp. 19-27, 2008.

[14] J. H. Flynn and L. A. Wall, "A quick direct method for the determination of activation energy from thermogravimetric data," Polymer Letters, vol. 4, pp. 323-328, 1966.

[15] H. L. Friedman, "Kinetics of thermal degradation of charforming plastics from thermogravimetry: application to phenolic plastic," Journal of Polymer Science Part C, vol. 6, pp. 183-195, 1965.

[16] H. E. Kissinger, "Reaction kinetics in thermal analysis," Analytical Chemistry, vol. 29, pp. 1702-1706, 1957.

[17] S. D. Kim and J. K. Park, "Characterization of thermal reaction by peak temperature and height of DTG curves," Thermochimica Acta, vol. 264, pp. 137-156, 1995.

[18] S. Vyazovkin, A. K. Burnham, J. M. Criado, L. A. PérezMaqueda, C. Popescu, and N. Sbirrazzuoli, "ICTAC Kinetics Committee recommendations for performing kinetic computations on thermal analysis data," Thermochimica Acta, vol. 520, no. 1-2, pp. 1-19, 2011.

[19] S. M. Shin and S. H. Kim, "Thermal decomposition behavior and durability evaluation of thermotropic liquid crysllaine polymers," Macromolecular Research, vol. 17, pp. 149-155, 2009.

[20] M. E. Brown, M. Maciejewski, S. Vyazovkin et al., "Computational aspects of kinetic analysis-part A: the ICTAC Kinetics Project-data, methods and results," Thermochimica Acta, vol. 355, no. 1-2, pp. 125-143, 2000.

[21] S. Vyazovkin and N. Sbirrazzuoli, "Isoconversional kinetic analysis of thermally stimulated processes in polymers," Macromolecular Rapid Communications, vol. 27, no. 18, pp. 1515-1532, 2006. 

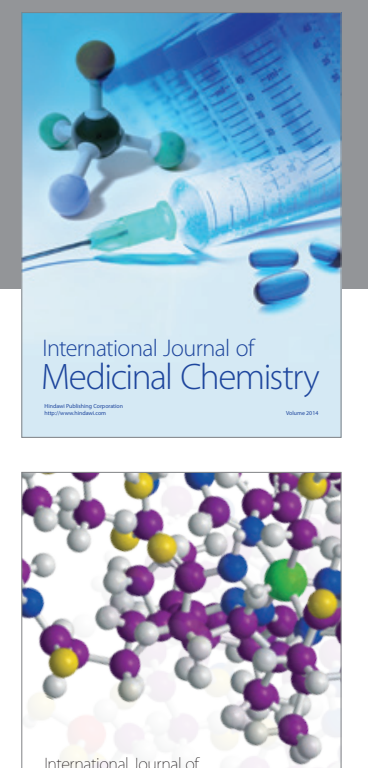

\section{Carbohydrate} Chemistry

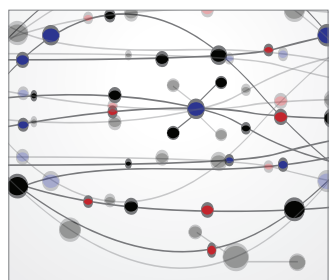

The Scientific World Journal
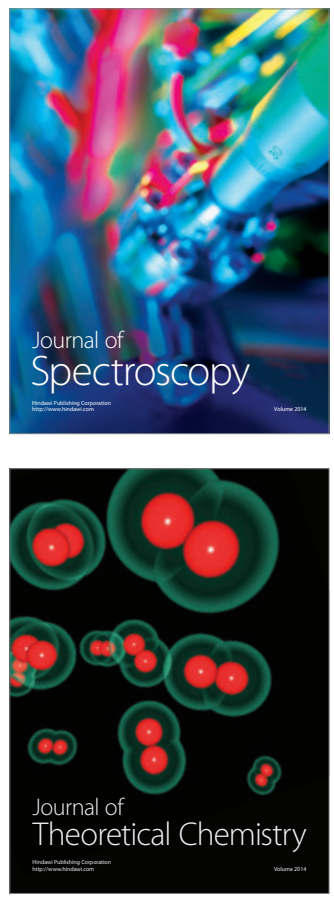
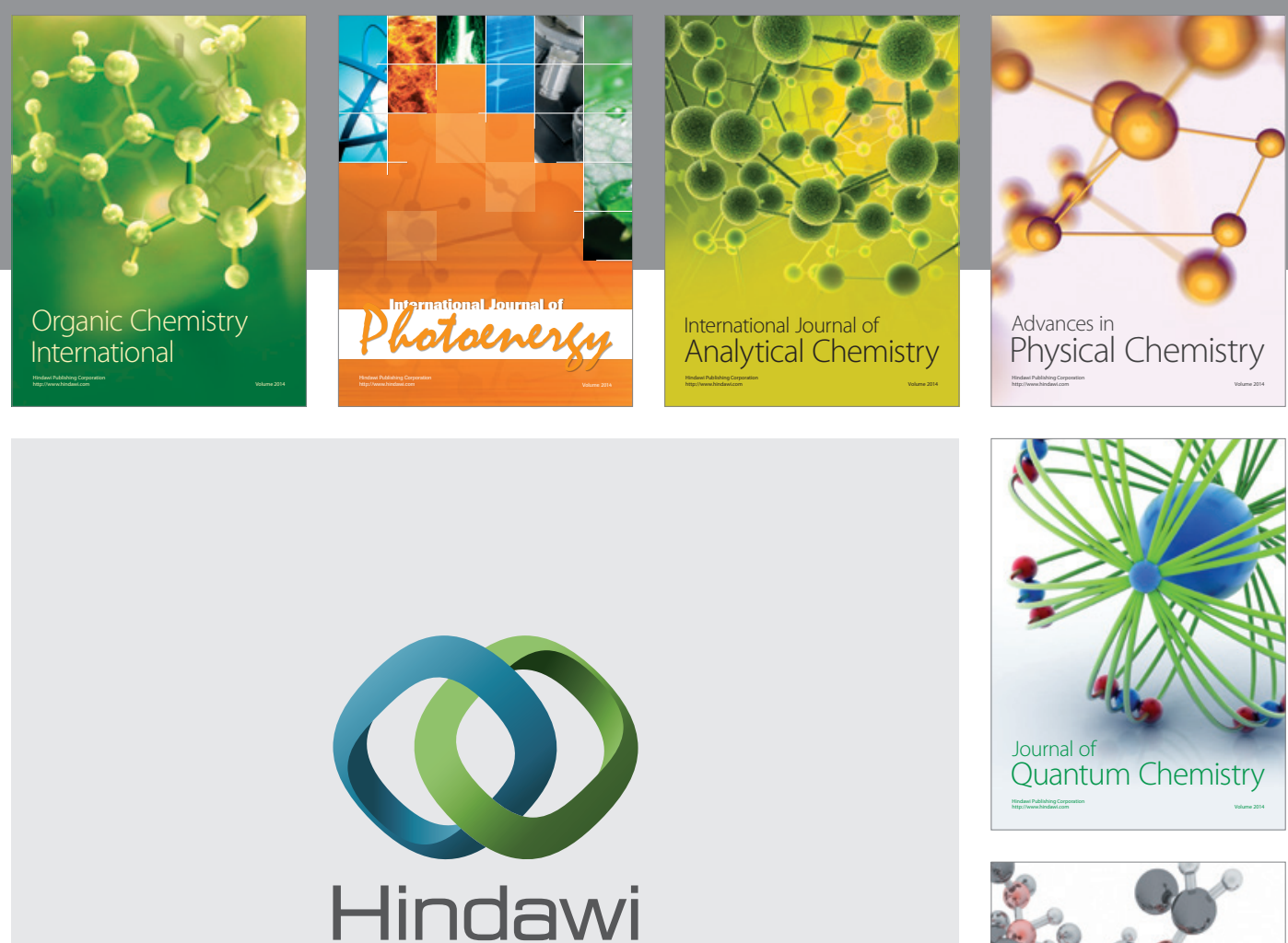

Submit your manuscripts at

http://www.hindawi.com

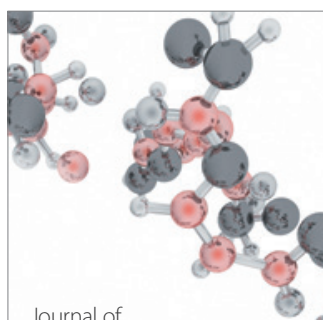

Analytical Methods

in Chemistry

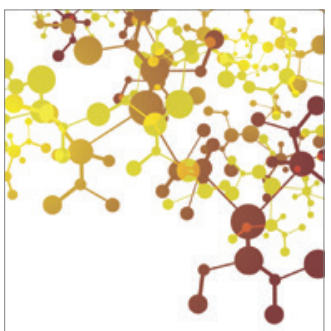

Journal of

Applied Chemistry

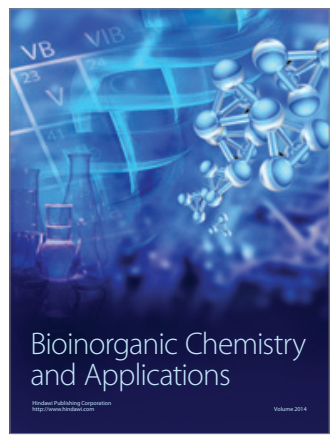

Inorganic Chemistry
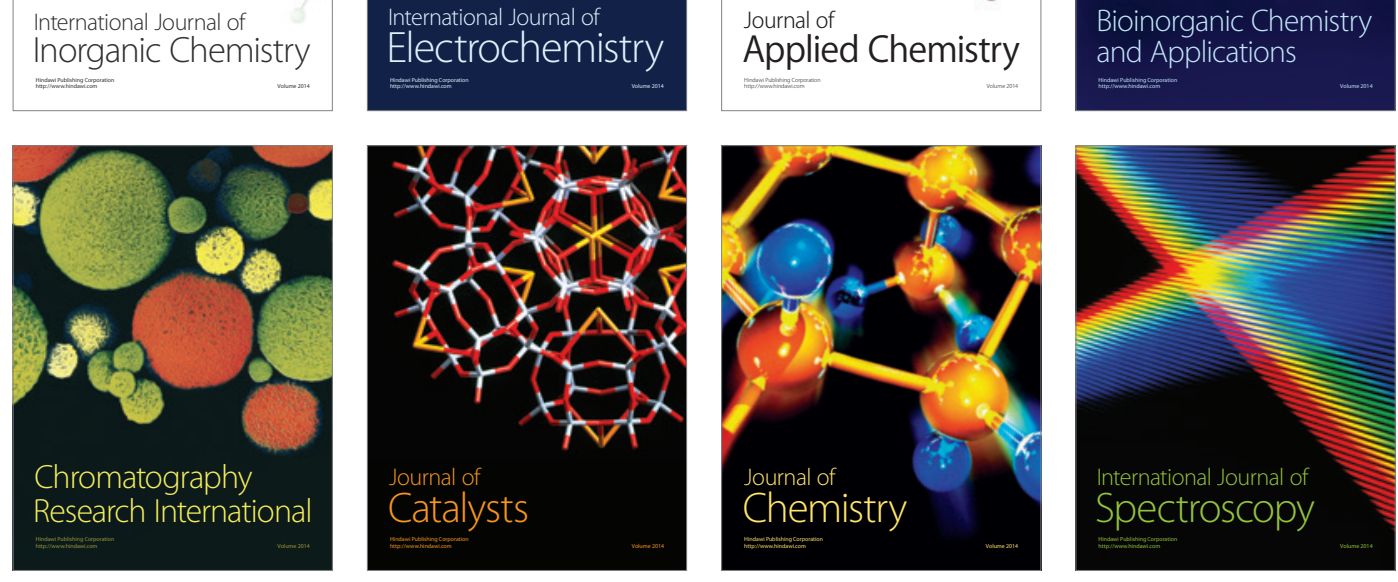